\title{
Overview of the US-Japan Collaborative Investigation on Hydrogen Isotope Retention in Neutron-Irradiated and Ion- Damaged Tungsten
}

ISFNT-10

Masashi Shimada

Y. Hatano

Y. Oya

T. Oda

M. Hara

G. Cao

M. Kobayashi

M. Sokolov

H. Watanabe

B. Tyburska-Püschel

Y. Ueda

P. Calderoni

K. Okuno

The INL is a

U.S. Department of Energy

National Laboratory

operated by

Battelle Energy Alliance

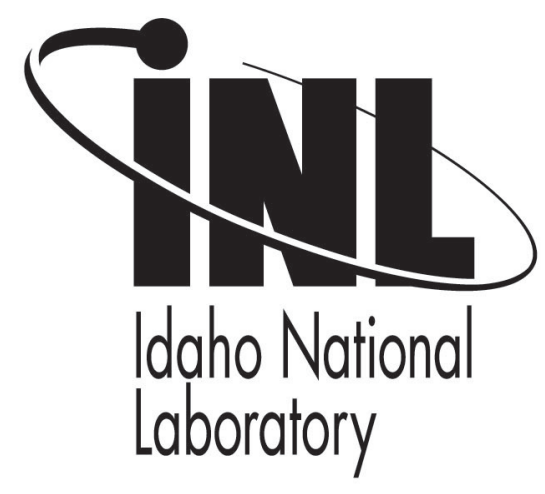

\section{September 2011}

This is a preprint of a paper intended for publication in a journal or proceedings. Since changes may be made before publication, this preprint should not be cited or reproduced without permission of the author. This document was prepared as an account of work sponsored by an agency of the United States Government. Neither the United States Government nor any agency thereof, or any of their employees, makes any warranty, expressed or implied, or assumes any legal liability or responsibility for any third party's use, or the results of such use, of any information, apparatus, product or process disclosed in this report, or represents that its use by such third party would not infringe privately owned rights. The views expressed in this paper are not necessarily those of the United States Government or the sponsoring agency. 


\title{
Overview of the US-Japan collaborative investigation on hydrogen isotope retention in neutron-irradiated and ion-damaged tungsten
}

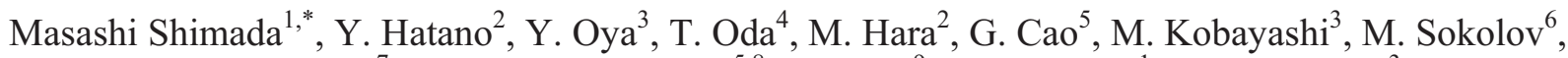 \\ H. Watanabe ${ }^{7}$, B. Tyburska-Püschel ${ }^{5,8}$, Y. Ueda $^{9}$, P. Calderoni ${ }^{1}$, and K. Okuno ${ }^{3}$ \\ ${ }^{1}$ Fusion Safety Program, Idaho National Laboratory, Idaho Falls, ID, U.S.A. \\ ${ }^{2}$ Hydrogen Isotope Research Center, University of Toyama, Toyama, Japan \\ ${ }^{3}$ Radioscience Research Laboratory, Faculty of Science, Shizuoka University, Shizuoka, Japan \\ ${ }^{4}$ Department of Nuclear Engineering and Management, The University of Tokyo, Tokyo, Japan \\ ${ }^{5}$ Department of Engineering Physics, University of Wisconsin-Madison, Madison, WI, U.S.A. \\ ${ }^{6}$ Oak Ridge National Laboratories, Oak Ridge, TN, U.S.A. \\ ${ }^{7}$ Research Institute for Applied Mechanics, Kyushu University, Fukuoka, Japan \\ ${ }^{8}$ Institute für Plasmaphysik, EURATOM Association, Garching, Germany \\ ${ }^{9}$ Graduate School of Engineering, Osaka University, Osaka, Japan
}

The effect of neutron-irradiation damage has been mainly simulated using high-energy ion bombardment. A recent MIT report (PSFC/RR-10-4, "An Assessment of the Current Data Affecting Tritium Retention and its Use to Project Towards T Retention in ITER”, Lipschultz, B. et. al., April, 2010) summarizes the observations from high-energy ion bombardment studies and illustrates the saturation trend in deuterium concentration due to damage from ion irradiation in tungsten and molybdenum above 1 displacement per atom (dpa). While this prior database of results is quite valuable for understanding the behavior of hydrogen isotopes in plasma facing components (PFCs), it does not encompass the full range of effects that must be considered in a practical fusion environment due to short penetration depth, damage gradient, high damage rate, and high primary knock-on atom (PKA) energy spectrum of the ion bombardment. In addition, neutrons change the elemental composition via transmutations, and create a high radiation environment inside PFCs, which influences the behavior of hydrogen isotope in PFCs, suggesting the utilization of fission reactors is necessary for neutron irradiation. Under the framework of the US-Japan TITAN program, tungsten samples (99.99 at. \% purity from A.L.M.T. Co.) were irradiated by fission neutrons in the High Flux Isotope Reactor (HFIR), Oak Ridge National Laboratory (ORNL), at 50 and $300 \mathrm{C}$ to $0.025,0.3$, and $2.4 \mathrm{dpa}$, and the investigation of deuterium retention in neutron-irradiated tungsten was performed in the Tritium Plasma Experiment (TPE), the unique high-flux linear plasma facility that can handle tritium, beryllium and activated materials. This paper reports the recent results from the comparison of iondamaged tungsten via various ion species $\left(2.8 \mathrm{MeV} \mathrm{Fe}^{2+}, 20 \mathrm{MeV} \mathrm{W}^{2+}\right.$, and $\left.700 \mathrm{keV} \mathrm{H}^{-}\right)$with that from neutron-irradiated tungsten to identify the similarities and differences among them.

Keywords: neutron-irradiation, tungsten, tritium retention, ion-damage, liner plasma device, neutron

*Corresponding author tel: +1-208-533-4472

\section{Introduction}

Plasma-facing components (PFCs) will be exposed to 14 $\mathrm{MeV}$ neutrons from D-T fusion reactions, and tungsten, a candidate material for the divertor PFC in ITER, is expected to receive a neutron dose of 0.7 displacement per atom (dpa) by the end of operation in ITER [1]. The effect of neutron-irradiation damage has been mainly simulated using high-energy ion bombardment at different linear plasma devices or ion-implantation experiments with different tungsten materials [2-7]. A recent MIT report (written by members of the Divertor/Scrape-Off Layer subgroup of the International Tokamak Physics Activity) summarizes the observations from high-energy ion bombardment studies and illustrates the saturation trend in deuterium concentration due to damage from ion irradiation in tungsten and molybdenum above 1 dpa [8].

The ions are limited in range to only a few microns into the surface, the primary knock-on atom (PKA) energy (>
$\mathrm{MeV}$ ) from high energy ion-bombardment is much higher than that $(<300 \mathrm{keV})$ from $14 \mathrm{MeV}$ neutrons, and the displacement rate $\left(10^{-3} \sim 10^{-4} \mathrm{dpa} / \mathrm{sec}\right)$ from high energy ion-bombardment are three to four orders of magnitude higher than that $\left(10^{-7} \sim 10^{-8} \mathrm{dpa} / \mathrm{sec}\right)$ from fission and fusion neutron environments [9]. In addition, the $14 \mathrm{MeV}$ neutrons change the elemental composition via transmutations, and create a high radiation environment inside PFCs, which might have effects on the behavior of tritium in PFCs. Therefore, there still exists large uncertainty about the tritium retention in materials with neutron-radiation damage from the 14 $\mathrm{MeV}$ fusion neutrons. The effort to correlate among high-energy ions, fission neutrons, and fusion neutrons is crucial for accurately estimating tritium retention under a neutron-irradiation environment. In addition most of retention studies were carried out with different tungsten materials and different ion implantation or linear plasma devices, and the uncertainties associated with tungsten 
material and hydrogen isotope implantation need to be minimized.

Under the framework of the US-Japan TITAN (Tritium, Irradiation, and Thermofluids for America and Nippon) program, tungsten samples (99.99 at. \% purity from A.L.M.T. Co.) were irradiated by neutron in the High Flux Isotope Reactor (HFIR), ORNL, and the collaborative investigation of hydrogen isotope retention in neutron-irradiation and ion-damaged tungsten were performed using the Tritium Plasma Experiment (TPE), the unique high-flux linear plasma facility that can handle tritium, beryllium and activated materials, in Idaho National Laboratory (INL). To date, most plasma wall interaction (PWI) studies in linear plasma devices have been carried out with either hydrogen or deuterium on non-activated materials. TPE is unique in that it combines four specialized elements: (a) the ability to handle tritium, (b) a divertor-relevant high-flux plasma, (c) the ability to handle radioactive materials, as well as (d) the ability to handle beryllium. Several reports of deuterium retention in neutron-irradiated and $\mathrm{Fe}^{2+}$ implanted tungsten exposed in TPE have been published previously under this framework [10-13].

This paper will give an overview of this collaborative investigation and discuss on-going comparison from iondamaged tungsten via various ion species $\left(2.8 \mathrm{MeV} \mathrm{Fe}^{2+}\right.$, $20 \mathrm{MeV} \mathrm{W}^{2+}$, and $700 \mathrm{keV} \mathrm{H}^{-}$) with that from neutronirradiated tungsten to identify the similarities and differences among them using identical tungsten samples and identical linear plasma device in order to minimize uncertainties associated with tungsten material and ion implantation experiment.

\section{Experimental Apparatus}

\subsection{Tungsten material}

The tungsten samples $(\phi 6 \mathrm{~mm} \times 0.2 \mathrm{~mm})$ were prepared by cutting polycrystalline tungsten rod (99.99 at. \% purity, from A.L.M.T. Corp.) annealed at $900 \mathrm{C}$ for 0.5 hour in a hydrogen atmosphere to relieve internal stresses in the manufacturing process. The samples were mechanically polished to a mirror finish, and then annealed at $900 \mathrm{C}$ for 0.5 hour in ultra high vacuum $\left(\sim 10^{-6} \mathrm{~Pa}\right)$ prior to plasma exposure. The grains are elongated along the direction normal to the plasmaexposed surface, which is similar to ITER grade tungsten for the purpose of minimizing large blister formation and improving heat transfer.

\subsection{Neutron-irradiation}

Tungsten samples were irradiated to three different damage levels $(0.025,0.3$, and $2.4 \mathrm{dpa})$ under the TITAN program. The first set of tungsten samples were irradiated for 33 hours by high-flux neutrons at $50 \mathrm{C}$ to $0.025 \mathrm{dpa}$ in HFIR, ORNL in January 2009. The thermal neutron flux and fluence at the irradiation location are $2.5 \times 10^{19} \mathrm{n} / \mathrm{m}^{2} \mathrm{~s}$, and $3.0 \times 10^{24} \mathrm{n} / \mathrm{m}^{2}$ respectively. The fast neutron $(>0.1 \mathrm{MeV})$ flux and fluence are $8.9 \times 10^{18} \mathrm{n} / \mathrm{m}^{2} \mathrm{~s}$, and $1.1 \times 10^{24} \mathrm{n} / \mathrm{m}^{2}$ respectively. The set of tungsten samples were sealed in a molybdenum envelope in the aluminum "rabbit" to prevent cooling water leakage onto the samples but allowing enough heat conduction for the sample to be cooled down to the cooling water temperature during the neutron irradiation [10]. The rabbit was transferred via the HFIR hydraulic tube facility to irradiate tungsten samples at $50 \mathrm{C}$ for the required irradiation time (33 hours), which is less than the standard HFIR operating cycle to reach the desired damage creation of $0.025 \mathrm{dpa}$. Although all the irradiation campaign have been completed, the testing of the 0.3 and 2.4 dpa samples have not yet been carried out due to their high radioactivity and dose rate. Only the results from the first sets $(0.025 \mathrm{dpa})$ of neutron-irradiated tungsten are discussed in this paper.

\subsection{Damage simulation using high-energy ion beam}

Three different types of ion-damaged tungsten are prepared to simulate the displacement damage from 14 $\mathrm{MeV}$ neutron-irradiation. The identical tungsten samples were used for both neutron-irradiation and ionimplantation. Figure 1 shows the damage profile from three different high-energy ion beams by SRIM 2008 calculation using the displacement energy of $90 \mathrm{eV}$ [14]. There are four orders of magnitude in the vacancy creation per ion: i.e. $\mathrm{W}^{2+}$ ions create four orders of magnitude more damages than that of $\mathrm{H}^{-}$ions at the same ion fluence. Therefore, four orders of magnitude more $\mathrm{H}^{-}$ ion fluence is required to create the identical displacement damage from $\mathrm{W}^{2+}$ ions. The maximum ion penetration depth are around 1.3, 2.4, and $3.9 \mu \mathrm{m}$ for 2.8 $\mathrm{MeV} \mathrm{Fe}^{2+}$, $20 \mathrm{MeV} \mathrm{W}^{2+}$, and $0.7 \mathrm{MeV} \mathrm{H}^{-}$ions, respectively.

The notable difference in the profile is that the $0.7 \mathrm{MeV}$ $\mathrm{H}^{-}$has flat profile region up to $1.5 \mu \mathrm{m}$ from the surface, whereas the $2.8 \mathrm{MeV} \mathrm{Fe}^{2+}$ and $20 \mathrm{MeV} \mathrm{W}^{2+}$ do not have flat region.

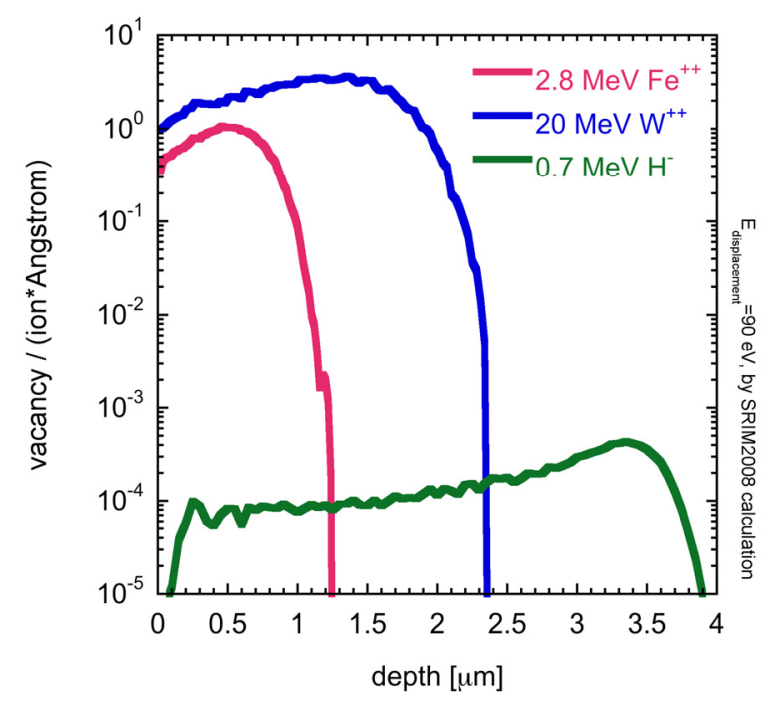

Fig. 1. Damage profile from three different high-energy ion beams by SRIM 2008 calculation.

\subsection{1 $\mathrm{Fe}^{2+}$ implanted tungsten}


The $2.8 \mathrm{MeV} \mathrm{Fe}^{2+}$ ions were implanted into tungsten at room temperature by the Tandetron Accelerator, RAPID (Rutherford backscattering spectroscopic Analyzer with Particle induced $\mathrm{x}$-ray Emission and Ion implantation Devices), at the University of Tokyo, Japan. Three different damaged samples were prepared by changing the ion fluences of $2.7 \times 10^{17}, 3.3 \times 10^{18}$ and $3.3 \times 10^{19}$ $\mathrm{Fe}^{2+} \mathrm{m}^{-2}$, which corresponded to the $0.027 \mathrm{dpa}, 0.3 \mathrm{dpa}$ and $3.0 \mathrm{dpa}$, respectively, at the peak region around 0.8 $\mu \mathrm{m}$ from the surface [13]. The displacement energy of $90 \mathrm{eV}$ was used for the damage calculation.

\subsection{2 $\mathrm{W}^{2+}$ implanted tungsten}

The $20 \mathrm{MeV} \mathrm{W}^{2+}$ ions were implanted into tungsten at room temperature at IPP Garching, Germany. Two different damaged samples were prepared by changing the ion fluences of $4.7 \times 10^{17}$, and $4.7 \times 10^{18} \mathrm{~W}^{2+} \mathrm{m}^{-2}$, which corresponded to 0.3 and $3.0 \mathrm{dpa}$, respectively at the peak around $1.3 \mu \mathrm{m}$ from the surface [3]. The displacement energy of $90 \mathrm{eV}$ was used for the damage calculation.

\subsection{3 $\mathrm{H}^{-}$implanted tungsten}

The $0.7 \mathrm{MeV} \mathrm{H}^{-}$ions were implanted into tungsten at room temperature by the $1 \mathrm{MeV}$ accelerator MTF, at JAEA, Japan. The damaged samples were prepared by changing the ion fluences of $1.4 \times 10^{22} \mathrm{H}^{-} \mathrm{m}^{-2}$, which corresponded to $0.48 \mathrm{dpa}$ at the flat region around 1.0 $\mu \mathrm{m}$ from the surface [4]. The displacement energy of 40 $\mathrm{eV}$ was used for the damage calculation, which gives a factor of 2-3 higher damage value compared with the one calculated with $90 \mathrm{eV}$.

\subsection{Deuterium plasma exposure}

After ten months cooling in light water following the neutron-irradiation or after several weeks after highenergy ion implantation, the neutron-irradiated and iondamaged tungsten samples were shipped to the Safety Tritium Applied Research (STAR) facility at INL for the plasma exposure. TPE at INL was used to implant low energy $(100 \mathrm{eV})$ deuterons in the neutron-irradiated tungsten, ion-damaged tungsten and unirradiated tungsten. All tungsten samples were exposed to similar high-flux deuterium plasma conditions (ion flux: (5-7) $\mathrm{x} 10^{21} \mathrm{~m}^{-2} \mathrm{~s}^{-1}$, ion fluence: $\left.(5-7) \times 10^{25} \mathrm{~m}^{-2}\right)$ at the same sample temperature of $473 \mathrm{~K}(200 \mathrm{C})$ in TPE. Incident ion energy of $100 \mathrm{eV}$ was achieved by adjusting the target bias voltage. The stage III and the stage IV recoveries of neutron-irradiated tungsten are reported to occur around $550 \mathrm{~K}\left(0.15 T_{m}\right.$, where $T_{m}$ is the melting temperature of tungsten, $3695 \mathrm{~K})$ and $1050 \mathrm{~K}\left(0.31 T_{m}\right)$, respectively [15]. For the sample exposed at $473 \mathrm{~K}$ (200C), the sample temperature was kept below the stage III recovery temperature of $550 \mathrm{~K}\left(0.15 T_{m}\right)$ to prevent recovery of neutron-irradiated damage during the deuterium plasma exposure. The sample temperature was monitored by the ungrounded K-type thermocouple that was attached on the back of the sample.

\subsection{Thermal desorption spectroscopy}

After plasma exposure, the samples were removed from TPE, and the amount of retained $\mathrm{D}$ was determined via a thermal desorption spectroscopy (TDS) system. While some exposure to air was unavoidable during this process, a continuous Ar purge served to mitigate any sample contamination during placement in the TDS system. The vacuum facility consisted of an analysis chamber equipped with a Dycor 50 amu residual gas analyzer (RGA). The main chamber was attached to a Pfieffer $70 \mathrm{l} / \mathrm{s}$ turbo molecular pump, capable of maintaining a base pressure of $4 \times 10^{-6} \mathrm{~Pa}$ after bake-out. The analysis chamber was attached to a double-ended quartz tube enclosed in a cylindrical furnace for sample heating. During this process, a tantalum tray held the sample in place. Two K-type thermocouples monitored the process temperature. Three standard leaks provided an absolute $\mathrm{D}_{2}$ sensitivity calibration for the RGA. We used a slower ramp rate of $10 \mathrm{C} / \mathrm{min}$ for thermal desorption, and the final temperature of $900 \mathrm{C}$ was maintained for $30 \mathrm{~min}$. A background desorption spectrum was established by heating a virgin sample. Only the peaks associated with $\mathrm{D}_{2}$ and HD peaks were considered in this analysis, and the same RGA sensitivity was assumed for both.

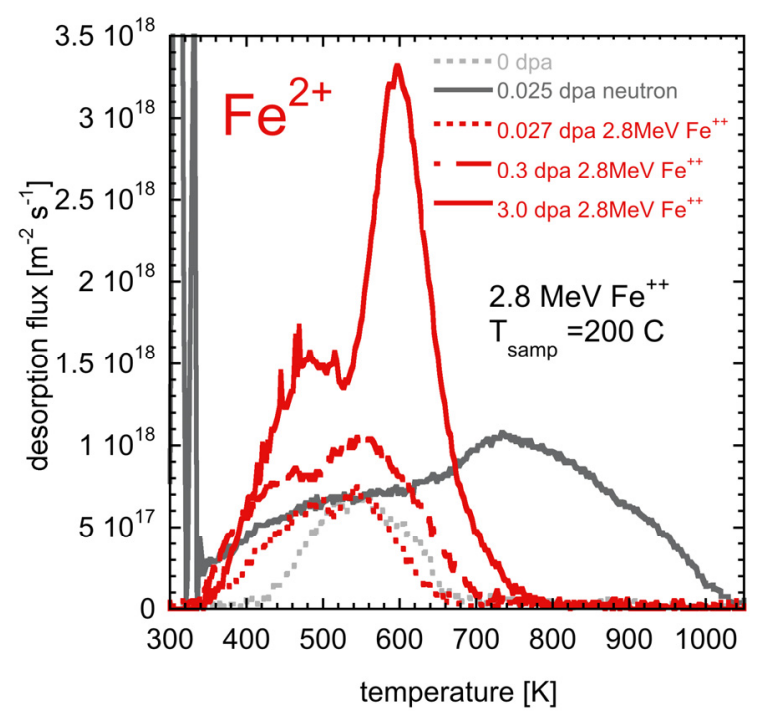

Fig. 2. Thermal desorption spectra from $\mathrm{Fe}^{2+}$ implanted tungsten (to the displacement damage of $0.027,0.3$, and 3.0 dpa) exposed to similar plasma conditions at the identical sample temperature of $200 \mathrm{C}$. The gray dotted line and grey solid lines in all figures are from unirradiated (0 dpa) and neutron-irradiated $(0.025 \mathrm{dpa})$ tungsten, respectively, for comparison.

\section{Results and discussions}

Figures 2 and 3 show the thermal desorption spectra from three different ion-damaged tungsten samples exposed to similar plasma conditions at the identical sample temperature of $200 \mathrm{C}$. The identical tungsten samples $(\phi 6 \mathrm{~mm} \times 0.2 \mathrm{~mm}, 99.99$ at. \% purity) from A.L.M.T. Corp. were used for both neutron-irradiation 
and ion-implantation. Both $\mathrm{x}$-axis and $\mathrm{y}$-axis are in the same scale in both figures for readability. The gray dotted line and grey solid lines in both figures are from unirradiated (0 dpa) and neutron-irradiated (0.025 dpa) tungsten, respectively, for comparison. A narrow spectrum from 450 to $700 \mathrm{~K}$ was observed from unirradiated ( $0 \mathrm{dpa}$ ) tungsten, and a broad TDS spectrum (300-1000 K) was observed from neutron-irradiated $(0.025 \mathrm{dpa})$ tungsten. Note that the two distinctive peaks were associated with two temperature jumps at the beginning of the desorption cycle. This might be due to the oxide formation during irradiation [10].

Figure 2 shows the TDS spectra from $\mathrm{Fe}^{2+}$ implanted tungsten to the displacement damage of $0.027,0.3$, and $3.0 \mathrm{dpa}$. The peak intensity increases and the spectra shapes look identical as the damage increase from 0.027 to $0.3 \mathrm{dpa}$. The peak intensity increases significantly and the two peaks position shifts to higher temperature as the damage increase from 0.3 to $3.0 \mathrm{dpa}$. The cause of the spectrum change might be associated with the dislocation loops observed in Oya et al [13]. The tail of TDS spectra shift to higher temperature as the displacement damage increases.

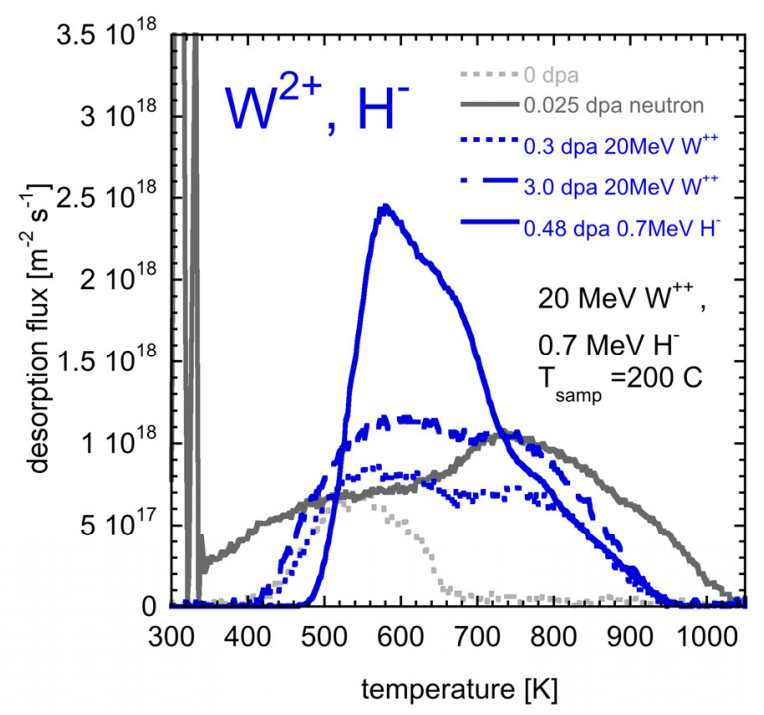

Fig. 3. Thermal desorption spectra from $\mathrm{W}^{2+}$ implanted tungsten (to the displacement damage of 0.3 and $3.0 \mathrm{dpa}$ ) and $\mathrm{H}^{-}$implanted tungsten (to the displacement damage of 0.48 dpa) exposed to similar plasma conditions at the identical sample temperature of $200 \mathrm{C}$. The gray dotted line and grey solid lines in all figures are from unirradiated $(0 \mathrm{dpa})$ and neutron-irradiated $(0.025 \mathrm{dpa})$ tungsten, respectively, for comparison.

Figure 3 shows the TDS spectra from $\mathrm{W}^{2+}$ implanted tungsten to the displacement damage of 0.3 and $3.0 \mathrm{dpa}$, and $\mathrm{H}^{-}$implanted tungsten to the displacement damage of $0.48 \mathrm{dpa}$. For $\mathrm{W}^{2+}$ implanted tungsten, the peak intensity increases and the spectra shapes look identical as the damage increase from 0.3 to $3.0 \mathrm{dpa}$. Interesting point to note is that the desorption starts and ends at the identical temperature from 0.3 to $3.0 \mathrm{dpa}$. The observed TDS spectrum looks identical to the reported spectrum by Tyburska et. al [3]. For the $\mathrm{H}^{-}$implanted tungsten, there observed the sharp increase in desorption spectrum, and long tail up to $950 \mathrm{~K}$. The observed TDS spectrum looks identical to the reported spectrum by Fukumoto et. al [4]. Unfortunately one displacement damage sample has been tested at this moment. The $\mathrm{W}^{2+}$ and $\mathrm{H}^{-}$iondamaged tungstens have similar profiles around 800-950 $\mathrm{K}$. This tail might be associated with delayed release of deuterium atom from bulk by trapping/de-trapping at empty traps. The depth profile and modeling are necessary to reveal this mechanism, and it is beyond scope of this paper.

When comparing TDS spectra in Figure 2 and 3, one can see that $\mathrm{Fe}^{2+}$ ions reproduce the lower temperature TDS peaks $(300-700 \mathrm{~K})$, and $\mathrm{H}^{-}$and $\mathrm{W}^{2+}$ ions reproduce the medium temperature TDS peaks (450-900 K). None of the high-energy ion beams were able to simulate the broad TDS spectrum $(300-1000 \mathrm{~K})$ by the HFIR neutrons, especially the high temperature peak $(>900$ $\mathrm{K})$. Interesting point to note is that the tail of TDS spectra of the $\mathrm{W}^{2+}$ and $\mathrm{H}^{-}$give identical profile from 800 to $950 \mathrm{~K}$.

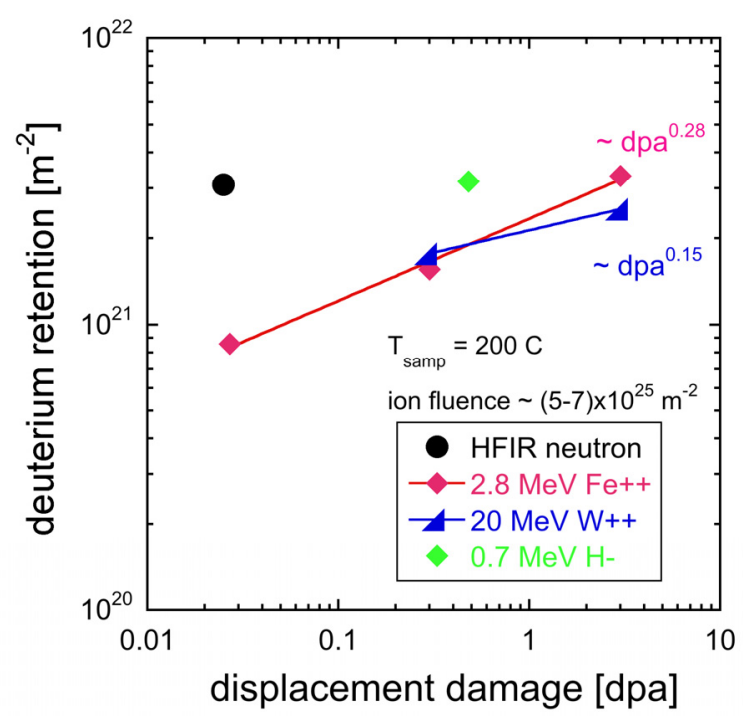

Fig. 4. Deuterium retention from three different high-energy ion beam and neutron-irradiated tungsten exposed to similar plasma condition at the sample temperature of $200 \mathrm{C}$.

Figure 4 illustrates the deuterium retention from three different high-energy ion beam and neutron-irradiated tungsten samples exposed to similar plasma condition at the sample temperature of $200 \mathrm{C}$.

For the $\mathrm{Fe}^{2+}$ damaged tungsten, deuterium retention increases as $\mathrm{dpa}^{0.28}$, whereas it increases as $\mathrm{dpa}^{0.15}$ for the $\mathrm{W}^{2+}$ damaged tungsten. No sign of saturation was yet observed for the ion damaged tungsten below $3 \mathrm{dpa}$, and further experiment at higher damaged $(>3 \mathrm{dpa})$ is necessary to investigate the saturation trend reported in deuterium concentration due to damage from ion irradiation in tungsten above $1 \mathrm{dpa}$ [8]. The cause of the different dependence is unknown at this point. Deuterium retention from $0.025 \mathrm{dpa}$ HFIR neutrons is 
similar to that from 3.0 dpa $\mathrm{Fe}^{2+}$ and $\mathrm{W}^{2+}$ despite the 2 orders of magnitude difference in dpa. This could be due to the shallow implantation depth of only to a few $\mu \mathrm{m}$ via high-energy ion beam whereas there is a deep damage profile throughout the sample thickness of 200 $\mu \mathrm{m}$ via neutron-irradiation or the difference in the damage creation rate between neutron-irradiation $\left(10^{-}\right.$ $\left.{ }^{7} \sim 10^{-8} \mathrm{dpa} / \mathrm{sec}\right)$ and ion-damage simulation $\left(10^{-3} \sim 10^{-4}\right.$ $\mathrm{dpa} / \mathrm{sec})$.

Please note that the displacement energy used for the damage calculation of $\mathrm{H}^{-}$was different $\left(E_{d}=40 \mathrm{eV}\right)$ from the value $\left(\mathrm{E}_{\mathrm{d}}=90 \mathrm{eV}\right)$ used for $\mathrm{Fe}^{2+}$ and $\mathrm{W}^{2+}$, and the depth which the displacement damage was determined were $0.8,1.3$, and $1.0 \mu \mathrm{m}$ for $\mathrm{Fe}^{2+}, \mathrm{W}^{2+}$, and $\mathrm{H}^{-}$, respectively. These differences make it difficult to evaluate the deuterium retention results with the displacement damage (dpa) value only. For example, the displacement damage of $0.48 \mathrm{dpa}$ at $1.0 \mu \mathrm{m}$ with $E_{d}=40$ $\mathrm{eV}$ becomes $0.16 \mathrm{dpa}$ with $E_{d}=90 \mathrm{eV}$, but the peak displacement around $3.5 \mu \mathrm{m}$ is $0.9 \mathrm{dpa}$ even with $E_{d}=90$ $\mathrm{eV}$.

\section{Conclusions}

The three different $\left(2.8 \mathrm{MeV} \mathrm{Fe}^{2+}, 20 \mathrm{MeV} \mathrm{W}^{2+}\right.$, and $700 \mathrm{keV} \mathrm{H}^{-}$) high-energy ion-damaged tungsten samples were exposed to similar high-flux deuterium plasma conditions (ion flux: (5-7) $\times 10^{21} \mathrm{~m}^{-2} \mathrm{~s}^{-1}$, ion fluence: (5-7) $\left.\mathrm{x} 10^{25} \mathrm{~m}^{-2}\right)$ at the same sample temperature of $473 \mathrm{~K}(200$ $\mathrm{C})$ in TPE. The comparison of the results from iondamaged tungsten via various ion species $\left(2.8 \mathrm{MeV} \mathrm{Fe}^{2+}\right.$, $20 \mathrm{MeV} \mathrm{W}^{2+}$, and $700 \mathrm{keV} \mathrm{H}^{-}$) with that from neutronirradiated tungsten shows both the similarities and differences among them. The similarities are that $\mathrm{Fe}^{2+}$ ions reproduce the lower temperature TDS peaks (300$700 \mathrm{~K})$, and $\mathrm{H}^{-}$and $\mathrm{W}^{2+}$ ions reproduce the medium temperature TDS peaks (450-900 K). None of the highenergy ion beam, however, was able to simulate the broad TDS spectrum (300-1000 K) by the HFIR neutron. $\mathrm{D}$ retention from $0.025 \mathrm{dpa}$ HFIR neutrons is similar to that from $3.0 \mathrm{dpa} \mathrm{Fe}^{2+}$ and $\mathrm{W}^{2+}$ despite the 2 orders of magnitude difference in dpa. These results are statistically not enough to draw conclusive remark at this point, and further investigation is necessary, especially the effort to correlate various high ion energy simulations $\left(\mathrm{H}^{-}, \mathrm{He}^{2+}, \mathrm{Si}^{2+}, \mathrm{Fe}^{2+}, \mathrm{W}^{2+}\right)$ and identify what each ion can/cannot simulate.

\section{Acknowledgments}

This work was prepared for the U.S. Department of Energy, Office of Fusion Energy Sciences, under the DOE Idaho Field Office contract number DE-AC0705ID14517. This work is a part of the collaborative research between Japan and the U.S. with TITAN (Tritium, Irradiation and Thermofluids for America and Nippon) project.
[1] H. Iida, V. Khripunov, L. Petrizzi and G. Federici, 2004 ITER Nuclear Analysis Report G 73 DDD 2 W 0

[2] W.R. Wampler, R. Doerner, Nucl. Fusion 49 (2009) 115023

[3] B. Tyburska, V.Kh. Alimov, O.V. Ogorodnikova, K. Schmid, K. Ertl, J. Nucl. Mater. 395,(2009) 150

[4] M. Fukumoto, H. Kashiwagi, Y. Ohtsuka, Y. Ueda, M. Taniguchi, T. Inoue, K. Sakamoto, J. Yagyu, T. Arai, I. Takagi, T. Kawamura, J. Nucl. Mater. 390-391 (2009) 572

[5] G.M.Wright, M. Mayer, K. Ertl, G. de Saint-Aubin, and J. Rapp, Nucl. Fusion 50 (2010) 075006

[6] A. van Veen, H.A. Filius, J. De Vries, K.R. Bijkerk, G.J. Rozing, and D. Segers, J. Nucl. Mater. 155-157 (1988) 1113

[7] B.M. Oliver, R.A. Causey, and S.A. Maloy, J. Nucl. Mater. 329-333 (2004) 977

[8] MIT report PSFC/RR-10-4, "An Assessment of the Current Data Affecting Tritium Retention and its Use to Project Towards T Retention in ITER”, Lipschultz, B. et. al., April (2010)

[9] S. Ishino, P.Schiller and a. F. Rowcliffe, J. Fusion. Energy. 8 (1989) 147

[10] M. Shimada, Y. Hatano, P. Calderoni, T. Oda, Y. Oya, M. Sokolov, K. Zhang, G. Cao, R. Kolasinski, and J. P. Sharpe, J. Nucl. Mater., 415 (2011) S667

[11] T. Oda, M. Shimada, K. Zhang, P. Calderoni, Y. Oya, M. Sokolov, K. Zhang, G. Cao, R. Kolasinski, J. P. Sharpe, and Y. Hatano, Fusion Science and Technology, 60 (2011) 1455

[12] M. Shimada, G. Cao, Y. Hatano, T. Oda, Y. Oya, M. Hara and P. Calderoni, Phys. Scr. T145 (2011) 014051

[13] Y. Oya, M. Shimada, M. Kobayashi, T. Oda, M. Hara, H. Watanabe, Y. Hatano, P. Calderoni and K. Okuno, Phys. Scr. T145 (2011) 014050

[14] http://srim.org, SRIM.

[15] L.K. Keys, J. Moteff, J. Nucl. Mater. 34 (1970) 260

\section{References}

